\title{
Influence of graphene oxide and carbon nanotubes on the fatigue properties of silica/styrene-butadiene rubber composites under uniaxial and multiaxial cyclic loading
}

\author{
Zongchao Xu \\ Beijing University of Chemical Technology \\ Stephen Jerrams \\ Technological University Dublin, stephen.jerrams@tudublin.ie \\ Hao Guo \\ Beijing University of Chemical Technology
}

See next page for additional authors

Follow this and additional works at: https://arrow.tudublin.ie/cerart

Part of the Polymer and Organic Materials Commons

\section{Recommended Citation \\ Zongchao Xu, Stephen Jerrams, Hao Guo, Yanfen Zhou, Liang Jiang, Yangyang Gao, Liqun Zhang, Li Liu, Shipeng Wen, Influence of graphene oxide and carbon nanotubes on the fatigue properties of silica/ styrene-butadiene rubber composites under uniaxial and multiaxial cyclic loading, International Journal of Fatigue, Volume 131, 2020, 105388, ISSN 0142-1123, DOI: 10.1016/j.ijfatigue.2019.105388.}

This Article is brought to you for free and open access by the Centre for Elastomer Research at ARROW@TU Dublin. It has been accepted for inclusion in Articles by an authorized administrator of ARROW@TU Dublin. For more information, please contact arrow.admin@tudublin.ie, aisling.coyne@tudublin.ie,gerard.connolly@tudublin.ie. Funder: National Key R\&D Program of China; National Natural Science Foundation of China; National Basic Research Program of China

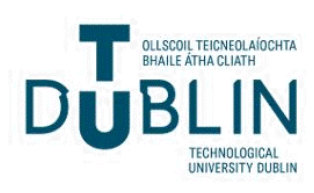




\section{Authors}

Zongchao Xu, Stephen Jerrams, Hao Guo, Yanfen Zhou, Liang Jiang, Yangyang Gao, Liqun Zhang, Li Liu, and Shipeng Wen

This article is available at ARROW@TU Dublin: https://arrow.tudublin.ie/cerart/22 


\title{
Influence of graphene oxide and carbon nanotubes on the fatigue properties of silica/styrene-butadiene rubber composites under uniaxial and multiaxial cyclic loading
}

\author{
Zongchao Xu ${ }^{\mathrm{a}, \mathrm{b}}$, Stephen Jerrams ${ }^{\mathrm{c}}$, Hao Guo ${ }^{\mathrm{a}, \mathrm{b}}$, Yanfen Zhou ${ }^{\mathrm{d}}$, Liang Jiang ${ }^{\mathrm{d}}$, Yangyang Gao ${ }^{\mathrm{a}, \mathrm{b}}$, \\ Liqun Zhang ${ }^{\mathrm{a}, \mathrm{b}}$, Li Liu ${ }^{\mathrm{a}, \mathrm{b}, *}$, Shipeng Wen ${ }^{\mathrm{a}, \mathrm{b}, *}$ \\ ${ }^{a}$ State Key Laboratory of Chemical Resource Engineering, Beijing University of Chemical Technology, Beijing 100029, China \\ ${ }^{\mathrm{b}}$ Beijing Engineering Research Center of Advanced Elastomers, Beijing University of Chemical Technology, Beijing 100029, China \\ ${ }^{\mathrm{c}}$ Centre for Elastomer Research, Technological University Dublin, Dublin, Ireland \\ ${ }^{\mathrm{d}}$ School of Textile and Garment, Qingdao University, Qingdao 266071, China
}

\section{A R T I C L E I N F O}

\section{Keywords:}

Rubber

Uniaxial fatigue

Multiaxial fatigue

Crack growth rate

Crack paths

\begin{abstract}
A B S T R A C T
The influence of equivalent replacement of silica $\left(\mathrm{SiO}_{2}\right)$ by carbon nanotubes (CNT) or graphene oxide (GO) on the microstructure, mechanical and fatigue behaviors of $\mathrm{SiO}_{2}$ /styrene-butadiene rubber (SBR) composites was investigated. Results showed that the synergistic effect between CNT (or GO) and $\mathrm{SiO}_{2}$ was beneficial for the filler network and improved the mechanical properties of SBR composites. Furthermore, the introduction of CNT (or GO) led to low crack growth rates and the crack propagation tips were easy to deflection. Under multiaxial fatigue conditions, the maximum engineering stress was determined to be a reliable fatigue life predictor for SBR composites.
\end{abstract}

\section{Introduction}

Styrene-butadiene rubber (SBR) is an important synthetic rubber which has been widely applied in automobile tires, wires and cables, tapes and other fields [1]. However, SBR matrices have poor mechanical properties and short fatigue lives due to a weak interaction between SBR molecules and a lack of strain-induced crystallization such as that which occurs in natural rubber (NR). Therefore, SBR requires reinforcement to improve its strength and fatigue life [2]. The fatigue life of rubber composites mainly depends on the initiation and propagation of microcracks, which can originate from the weak interface between filler aggregates and rubber molecules or original flaws in the rubber matrix. The microcracks will gradually enlarge into macroscopic cracks, which eventually lead to fatigue failure in rubber components $[3,4]$. Many factors have an influence on the fatigue failure behavior of rubber composites [5]. These include mechanical load history, environmental conditions, the composition and microstructures of rubber composites. In respect of rubber composition, nanofillers play a vital role in influencing mechanical properties and ultimate fatigue failure. It has been noted that the filler shape, filler dispersion, the interfaces between the fillers and the rubber molecules, and filler network in the rubber matrix all have effects on the fatigue failure of rubber composites [6-9].
In the rubber industry, spherical carbon black (CB) and silica $\left(\mathrm{SiO}_{2}\right)$ have a long history of being used as reinforcing fillers. Previous studies showed that the incorporation of $\mathrm{CB}$ and $\mathrm{SiO}_{2}$ into the rubber matrix significantly improved fatigue resistance in SBR [10-12]. Also, high loadings of $\mathrm{CB}$ and $\mathrm{SiO}_{2}$ were required to obtain high strength of rubber composites $[13,14]$. However, a large number of fillers tended to form aggregates in the rubber matrices, tending to induce stress concentrations and microcracks [15], which were harmful to the fatigue performance of rubber composites.

In recent years, carbon nanotubes (CNT), and graphene (GE) or its derivatives have increasingly attracted more attention in academic and industrial fields due to their large specific surface area, high mechanical strength, and excellent thermal and electrical conductivities [16]. Using CNT or GE, it is easy to form filler networks constituting relatively small loadings in rubber matrix, which is beneficial to mechanical properties. In particular, the filler networks constructed with CNT and GE having large aspect ratios can extend the crack propagation path in the composites, further resulting in longer fatigue lives. Dong et al. [17] prepared NR composites filled only with graphene oxide (GO). The fatigue crack growth resistance was remarkably enhanced with the incorporation of only $1 \mathrm{phr}$ of GO in sheet form. Li et al. [6] designed a compact hybrid filler network composed of GE and CNT to toughen NR.

\footnotetext{
* Corresponding authors at: State Key Laboratory of Chemical Resource Engineering, Beijing University of Chemical Technology, Beijing 100029, China.

E-mail addresses: liul@mail.buct.edu.cn (L. Liu), wensp@mail.buct.edu.cn (S. Wen).
} 
The hybrid filler network could be utilised as sacrificial bonds to dissipate energy prior to the failure of rubber, leading to resistance of fatigue crack growth. Zhou et al. [18] improved the crack resistance of natural rubber/solution polymerized butadiene styrene rubber (NR/ SSBR) composites by designing a filler network composed of GE, which preferentially broke and dissipated energy before the failure of the rubber composites.

Although CNT and GE can greatly improve the fatigue performance of rubber composites, currently their preparation cost is relatively high. It is impossible to replace all of the $\mathrm{CB}$ or $\mathrm{SiO}_{2}$ by $\mathrm{CNT}$ and/or GE in the manufacture of rubber components. Therefore, the most effective method is to partially replace the traditional fillers by CNT or GE. A small amount of CNT or GE in rubber composites not only ensures enhancement of the mechanical properties but also efficiently improves fatigue properties $[6,19]$.

The main objective in this research is to determine the influence of CNT or GO as a partial replacement of $\mathrm{SiO}_{2}$ on the microstructure, mechanical properties and fatigue behavior of $\mathrm{SiO}_{2} / \mathrm{SBR}$ composites under both uniaxial and multiaxial conditions. The CNT-SiO ${ }_{2}$ and GO$\mathrm{SiO}_{2}$ dispersion, filler network, mechanical and fatigue properties of the composites are discussed.

\section{Experimental section}

\subsection{Materials}

Styrene-butadiene rubber (SBR, 1502) latex was provided by the Qilu Petrochemical Company, China. GO was prepared by the modified Hummers method [20]. Silica $\left(\mathrm{SiO}_{2}\right.$, Ultrasil VN3) was supplied by Evonik Industries AG, Germany. Carbon nanotube bundles (Flotube ${ }^{\mathrm{TM}}$ 7000) were supplied by the Cnano Technology Co., Ltd. Bis(3-triethoxysilylpropyl)tetrasulfide (TESPT) was purchased from the Nanjing Shuguang Chemical Co., Ltd. Zinc oxide (ZnO), stearic acid (SA), poly (1,2-dihydro-2,2,4-trimethyl-quinoline) (antioxidant RD), N-(1, 3-dimethyl) butyl-N'-phenyl-p-phenylenediamine (antioxidant 4020), $\mathrm{N}$ cyclohexyl-2-benzothiazole sulfonamide (CZ), sulfur (S) were all commercially available.

\subsection{Preparation of SBR composites}

The formula for the SBR composites is shown in Table 1. According to our previous research [19] and other researchers' work [18], the content of CNT or GO in the composites has been chosen to be $3 \mathrm{phr}$. $\mathrm{SiO}_{2} / \mathrm{SBR}$ and CNT-SiO ${ }_{2} / \mathrm{SBR}$ composites were prepared by the traditional mechanical blending. To obtain the homogenous dispersion of GO in the SBR matrix, a GO/SBR masterbatch was first prepared by latex compounding [21]. Then $\mathrm{SiO}_{2}$ was mixed into the GO/SBR masterbatch by mechanical blending to obtain the final $\mathrm{GO}-\mathrm{SiO}_{2} / \mathrm{SBR}$ composites. It should be noted that $3 \mathrm{phr} \mathrm{SiO}_{2}$ was equally replaced by $\mathrm{CNT}$ and $\mathrm{GO}$ in both the $\mathrm{CNT}-\mathrm{SiO}_{2} / \mathrm{SBR}$ and $\mathrm{GO}-\mathrm{SiO}_{2} / \mathrm{SBR}$ composites.

Table 1

The formula of SBR composites, phr. ${ }^{\text {a }}$

\begin{tabular}{llll}
\hline Samples & $\mathrm{SiO}_{2} / \mathrm{SBR}$ & $\mathrm{CNT}-\mathrm{SiO}_{2} / \mathrm{SBR}$ & $\mathrm{GO}-\mathrm{SiO}_{2} / \mathrm{SBR}$ \\
\hline $\mathrm{SBR}$ & 100 & 100 & 100 \\
$\mathrm{ZnO}$ & 3.5 & 3.5 & 3.5 \\
$\mathrm{SA}$ & 1 & 1 & 1 \\
Antioxidant 4020 & 2 & 2 & 2 \\
Antioxidant $\mathrm{RD}$ & 2 & 2 & 2 \\
$\mathrm{CNT}$ & - & 3 & - \\
$\mathrm{GO}$ & - & - & 3 \\
$\mathrm{SiO}$ & & 47 & 47 \\
$\mathrm{TESPT}$ & 50 & 4.7 & 4.7 \\
$\mathrm{CZ}$ & 5 & 2.2 & 2.2 \\
$\mathrm{~S}$ & 2.2 & 1.4 & 1.4 \\
\hline
\end{tabular}

a phr: per hundred parts of rubbers.
The total filler content in the SBR composites was $50 \mathrm{phr}$. The vulcanization characteristics of SBR composites were obtained using an oscillating disc rheometer at $150{ }^{\circ} \mathrm{C}$. The composites were vulcanized for the optimum curing time at $150{ }^{\circ} \mathrm{C}$ and $15 \mathrm{MPa}$.

\subsection{Characterization}

The dispersion of fillers in the SBR matrix was observed by scanning electron microscopy (SEM, S4800, Hitachi, Japan) and transmission electron microscopy (TEM, Tecnai G2 20, FEI, USA). The filler network in the SBR matrix was characterized using a rubber process analyzer (RPA 2000, Alpha Technologies, USA) with a frequency of $1 \mathrm{~Hz}$ at $60{ }^{\circ} \mathrm{C}$. The dynamic properties of SBR composites were determined using a VA3000 (DMA, 01 dB-Metravib, France) in tension mode at a frequency of $10 \mathrm{~Hz}$ in the range of $-60{ }^{\circ} \mathrm{C}$ to $80{ }^{\circ} \mathrm{C}$ at a heating rate of $3{ }^{\circ} \mathrm{C} / \mathrm{min}$. The mechanical properties were established using an electrical tensile instrument (CMT4104, SANS Test Machine Co., Ltd., China). The tensile strength and tear strength tests were performed according to the standards ISO 37: 2011 and ISO 34-1: 2010, respectively. The fatigue properties were determined as follows:

\section{(1) Uniaxial fatigue testing}

The uniaxial crack growth rate was carried out on a dynamic mechanical analysis machine (DMA +1000 , Metravib, France) with a fatigue test procedure. Pure shear (PS) specimens $(40 \times 6 \times 2 \mathrm{~mm})$ were used in fatigue tests at $25^{\circ} \mathrm{C}$ at a frequency of $20 \mathrm{~Hz}$. Before the fatigue tests, 2000 dynamic cycles under a strain of $50 \%$ was carried out to ensure that no stress softening was observed [19]. Tearing energy (T) of the PS specimen was considered independent of the crack length [22] and can be expressed by the equation:

$T=w h_{0}$

where $w$ is the strain energy density and $h_{0}$ is the height of the specimen.

The evolution of storage modulus $\left(\mathrm{E}^{\prime}\right)$ and loss factor $(\tan \delta)$ of SBR composites were studied using the DMA +1000 machine at $80{ }^{\circ} \mathrm{C}$ with an amplitude of $10 \%$ and a frequency of $20 \mathrm{~Hz}$ for different cyclic loading cycles in the shear fatigue mode.

\section{(2) Multiaxial fatigue testing}

The multiaxial fatigue testing was conducted on a dynamic bubble inflation test system. The testing procedures used were described previously $[23,24]$. Two kinds of controlled fatigue tests were carried out: (1) In the cycles, the minimum stress $\left(\sigma_{\min }\right)$ for all samples was set at zero, and the maximum stress $\left(\sigma_{\max }\right)$ level varied between $5 \mathrm{MPa}$ and $9 \mathrm{MPa}$ and (2) the $\sigma_{\max }$ of all samples was set at $9 \mathrm{MPa}$, and the $\sigma_{\min }$ level varied between 0 and $4 \mathrm{MPa}$.

\section{Results and discussion}

\subsection{Filler dispersion in SBR composites}

The shape of the fillers has an important influence on the properties of the rubber composites. The morphologies of the $\mathrm{SiO}_{2}, \mathrm{CNT}$, and GO are shown in Fig. 1. In Fig. 1(a), the $\mathrm{SiO}_{2}$ particles exhibited a spherical shape and stuck together to form aggregates due to the strong hydrogen bonds between the $\mathrm{SiO}_{2}$ particles. In Fig. 1(b), CNT showed an entangled fiber shape because of their large aspect ratios. In Fig. 1(c), GO exhibited a large two-dimensional lamellar shape, and easily stacked together due to the strong van der Waals forces between the GO sheets.

The cryogenically fractured surface morphology reveals the dispersion of the filler and the interfacial interaction between the filler and the matrix. Fig. 2 shows the SEM images of cryogenically fractured surfaces for (a) $\mathrm{SBR}$, (b) $\mathrm{SiO}_{2} / \mathrm{SBR}$, (c) CNT-SiO $2 / \mathrm{SBR}$ and (d) $\mathrm{GO}_{-} \mathrm{SiO}_{2} /$ 

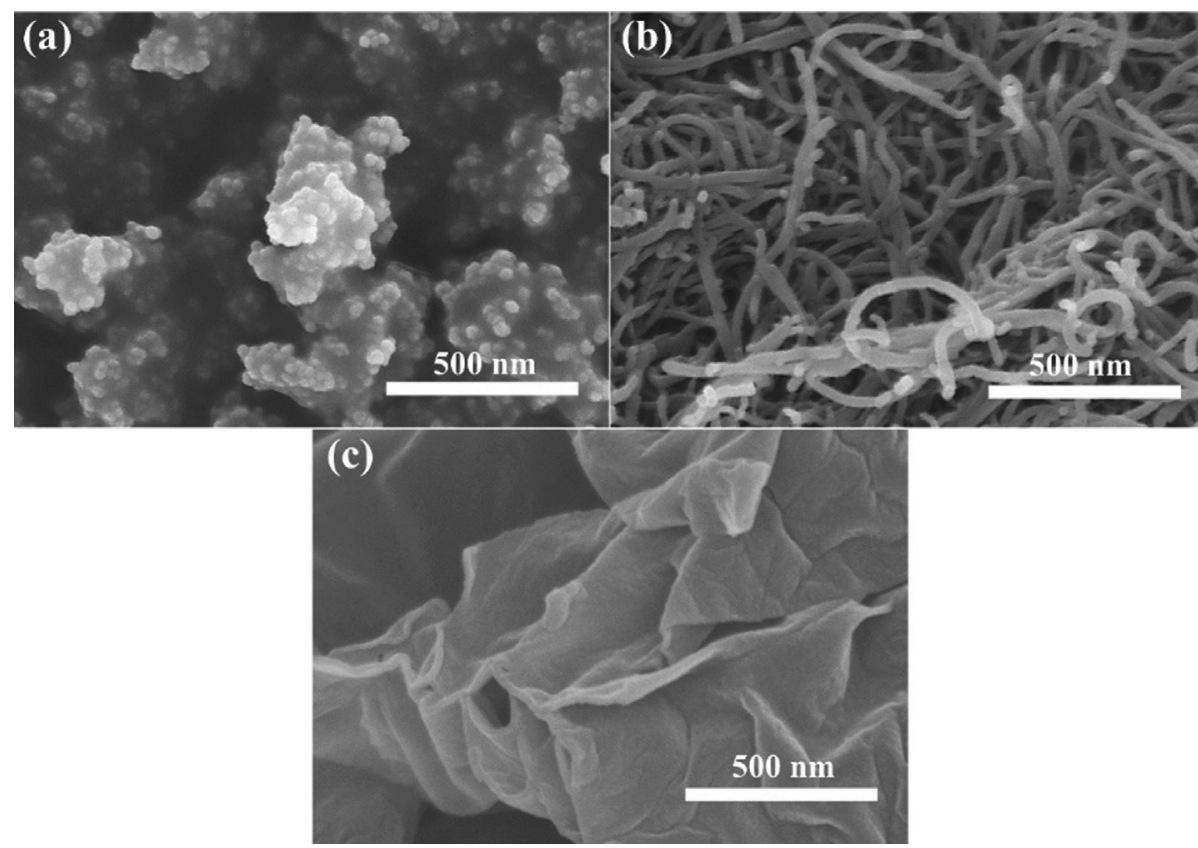

Fig. 1. SEM images of (a) $\mathrm{SiO}_{2}$, (b) CNT, (c) GO.

SBR composites. As shown in Fig. 2(a), it is clear that the cryogenically fractured surface of the pure SBR composites is flat and smooth. In Fig. 2(b), several large $\mathrm{SiO}_{2}$ particles (indicated by red circles) can be seen on the fractured surface due to the poor compatibility between $\mathrm{SiO}_{2}$ and nonpolar SBR matrix. In Fig. 2(c), CNT fibers appeared on the cryogenically fractured surface and were embedded in the SBR matrix. The particle size of $\mathrm{SiO}_{2}$ aggregates in the $\mathrm{CNT}-\mathrm{SiO}_{2} / \mathrm{SBR}$ composites was smaller than that in $\mathrm{SiO}_{2} / \mathrm{SBR}$ composites. In Fig. 2(d), the particle size of the $\mathrm{SiO}_{2}$ aggregates in $\mathrm{GO}-\mathrm{SiO}_{2} / \mathrm{SBR}$ composites further decreased. There was no obvious formation of aggregates and extraction of GO sheets on the fracture surface observed, suggesting good filler dispersion and strong interfacial adhesion between GO and the SBR matrix in the $\mathrm{GO}-\mathrm{SiO}_{2} / \mathrm{SBR}$ composites.

TEM observation was further carried out to provide visual evidence for the filler dispersion in the SBR matrix. In the TEM images, the bright color areas represent the rubber matrix and the black areas represent the filler aggregates due to the difference in mass thickness contrast between the rubber matrix and the fillers in the rubber composites [25]. In Fig. 3(a)\&(b), $\mathrm{SiO}_{2}$ particles dispersed unevenly in the SBR matrix and formed some large agglomerates marked by the regions encircled in red, owing to the formation of hydrogen bonds between the $\mathrm{SiO}_{2}$ particles [26]. In Fig. 3(c)\&(d), the bright areas of the SBR matrix and the dark areas of $\mathrm{SiO}_{2}$ aggregates clearly reduced. $\mathrm{SiO}_{2}$ particles were bridged through the tube-like CNT (as indicated by red arrows) to form a hybrid filler network. In Fig. 3(e)\&(f), the $\mathrm{SiO}_{2}$ aggregates in GO$\mathrm{SiO}_{2} / \mathrm{SBR}$ composites decreased, which was ascribed to the possible mechanism that exfoliated GO sheets (as indicated by red arrows) tended to penetrate into the $\mathrm{SiO}_{2}$ particles and facilitated the $\mathrm{SiO}_{2}$

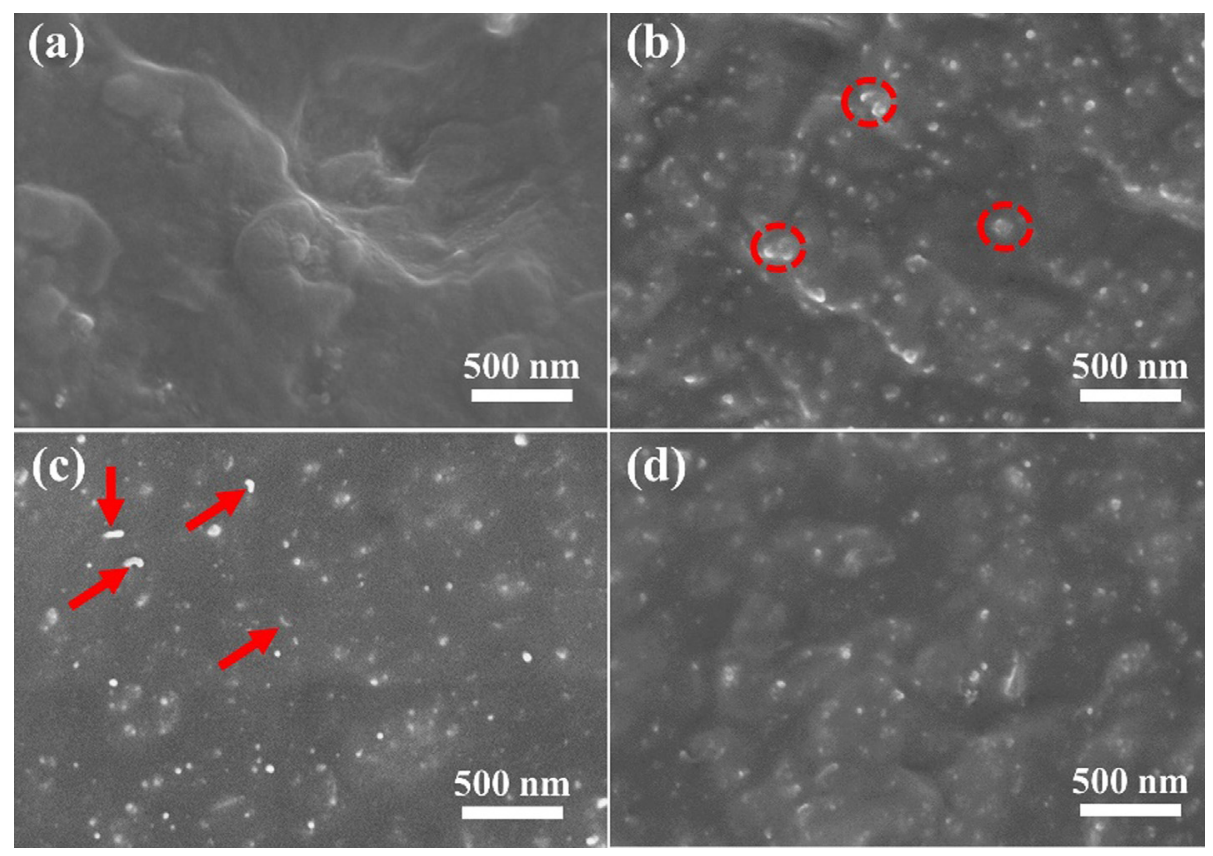

Fig. 2. SEM images of cryogenically fractured surfaces for (a) $\mathrm{SBR}$, (b) $\mathrm{SiO}_{2} / \mathrm{SBR}$, (c) $\mathrm{CNT}-\mathrm{SiO}_{2} / \mathrm{SBR}$, (d) $\mathrm{GO}_{-} \mathrm{SiO}_{2} / \mathrm{SBR}$ composites. 

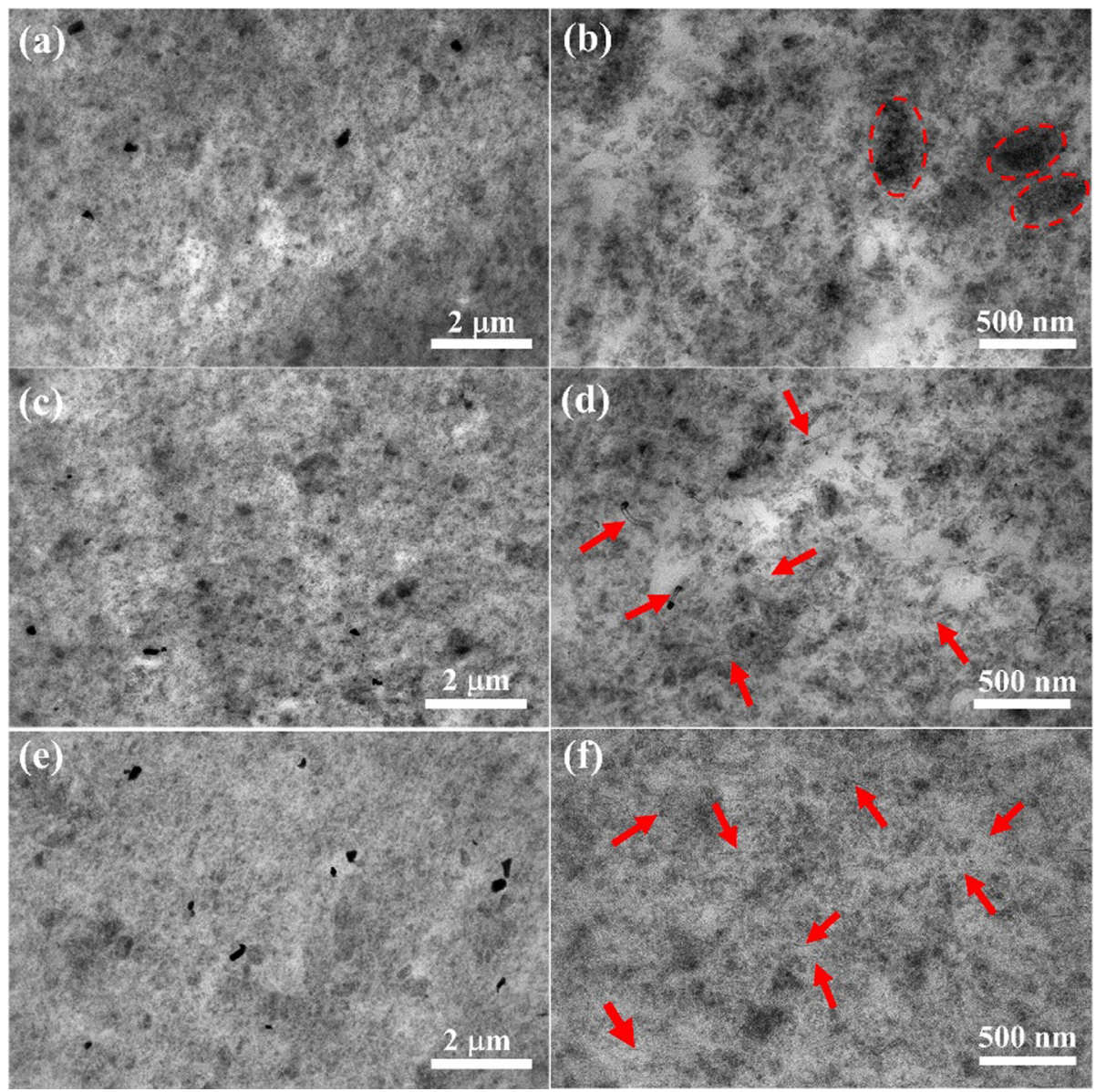

Fig. 3. TEM images of (a)\&(b) $\mathrm{SiO}_{2} / \mathrm{SBR}$, (c)\&(d) CNT-SiO${ }_{2} / \mathrm{SBR}$, (e)\&(f) $\mathrm{GO}^{-} \mathrm{SiO}_{2} / \mathrm{SBR}$ composites.

dispersion [27]. The strong $\mathrm{GO}^{-\mathrm{SiO}_{2}}$ synergistic filler network was beneficial to a valid load transfer and dissipated more energy during cyclic deformation, contributing to the dynamic crack resistance of the SBR composites.

\subsection{Filler network and dynamical properties}

The influence of the filler network is critical to the fatigue performance of the rubber composites [28]. The storage modulus $\left(\mathrm{G}^{\prime}\right)$ of rubber composites is closely related to the filler network. As shown in Fig. 4(a), the $\mathrm{G}^{\prime}$ of $\mathrm{CNT}-\mathrm{SiO}_{2} / \mathrm{SBR}$ and $\mathrm{GO}-\mathrm{SiO}_{2} / \mathrm{SBR}$ composites increased significantly after the introduction of CNT or GO into the $\mathrm{SiO}_{2}$ / SBR composites, due to their large specific surface area and aspect ratio, showing that the filler network of $\mathrm{GO}-\mathrm{SiO}_{2}$ gave more strength than that of the $\mathrm{CNT}-\mathrm{SiO}_{2}$ composites. The difference in storage modulus also suggests that the two-dimensional GO sheets could construct stronger filler networks than the virtually one-dimensional CNT. Fig. 4(b) shows the dependence of loss factor $(\tan \delta)$ on strain. With an increase in strain, the $\tan \delta$ increased gradually due to friction between the fillerfiller and filler-rubber molecules [27]. The loss factor of $\mathrm{CNT}-\mathrm{SiO}_{2} / \mathrm{SBR}$ or $\mathrm{GO}_{-} \mathrm{SiO}_{2} / \mathrm{SBR}$ composites was higher than that of $\mathrm{SiO}_{2} / \mathrm{SBR}$ composites, showing that the composite with filler network constructed by CNT-SiO ${ }_{2}$ or $\mathrm{GO}_{-} \mathrm{SiO}_{2}$ had strong interfacial friction and high energy dissipation under the same deformation.

In order to further characterize the interfacial interaction between different fillers and SBR molecules, DMA analysis of SBR composites was carried out. In Fig. 5(a), $\mathrm{E}^{\prime}$ for $\mathrm{GO}-\mathrm{SiO}_{2} / \mathrm{SBR}$ composites was higher than that of $\mathrm{CNT}-\mathrm{SiO}_{2} / \mathrm{SBR}$ and $\mathrm{SiO}_{2} / \mathrm{SBR}$ composites in both the glassy

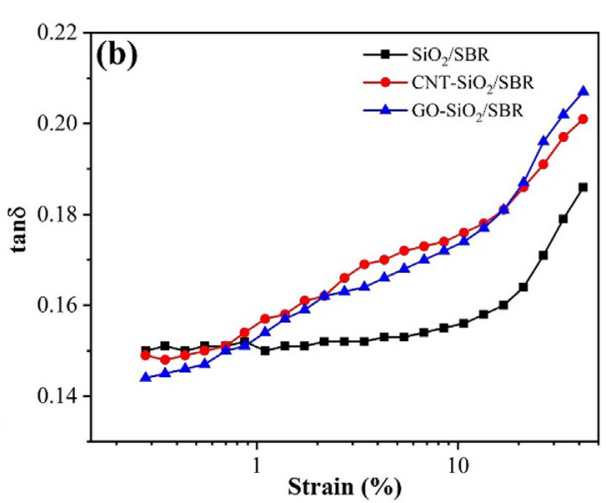

Fig. 4. (a) G'-strain curves of SBR compounds and (b) tan-strain curves of SBR vulcanizates. 

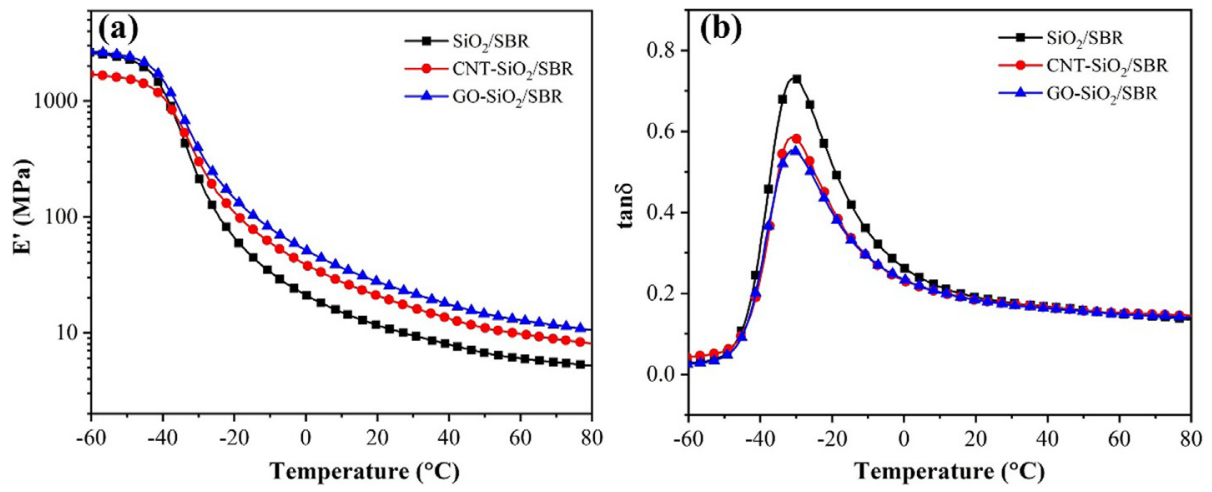

Fig. 5. The temperature dependence of (a) storage modulus and (b) loss factor for SBR composites.

and rubbery regions. For example, $\mathrm{E}^{\prime}$ for $\mathrm{GO}-\mathrm{SiO}_{2} / \mathrm{SBR}$ at $25{ }^{\circ} \mathrm{C}$ was $31.7 \%$ and $133 \%$ higher than that for $\mathrm{CNT}-\mathrm{SiO}_{2} / \mathrm{SBR}$ and $\mathrm{SiO}_{2} / \mathrm{SBR}$ composites respectively, indicating that the $\mathrm{GO}_{-} \mathrm{SiO}_{2}$ filler network efficiently reinforced the SBR matrix. In Fig. 5(b), the peak values of $\tan \delta$ for $\mathrm{GO}_{-} \mathrm{SiO}_{2} / \mathrm{SBR}$ and $\mathrm{CNT}-\mathrm{SiO}_{2} / \mathrm{SBR}$ composites decreased significantly, indicating that $\mathrm{GO}-\mathrm{SiO}_{2}$ and $\mathrm{CNT}-\mathrm{SiO}_{2}$ filler networks had a strong ability to restrict the rubber molecular chains. Also, compared with $\mathrm{CNT}-\mathrm{SiO}_{2}$ filled SBR composites, the two-dimensional lamellar GO in the GO-SiO 2 /SBR composites was easier to physically absorb more molecular chains, resulting in reducing the peak values of $\tan \delta$ for GO$\mathrm{SiO}_{2} / \mathrm{SBR}$ composites. This indicated that $\mathrm{GO}_{-} \mathrm{SiO}_{2}$ filler networks had stronger interfacial interactions with SBR matrices.

\subsection{Mechanical properties of SBR composites}

The filler dispersion and the interfacial interaction between fillers and rubber molecules have an important influence on the mechanical behavior of rubber composites. Fig. 6 and Table 2 show respectively the stress-strain curves and the mechanical data for SBR rubber composites. GO-SiO ${ }_{2} / \mathrm{SBR}$ and $\mathrm{CNT}_{-} \mathrm{SiO}_{2} / \mathrm{SBR}$ composites exhibited higher hardness, higher moduli $\sim 100 \%$ and $300 \%$ and tear strength than $\mathrm{SiO}_{2} / \mathrm{SBR}$ composites, because CNT and GO resulted in strong interfacial interactions with rubber matrices and formed more physical crosslinking points. CNT and GO limited the slip of SBR molecular chains during the tensile process, which resulted in a decrease in elongation at break of the SBR composites. The high tear strength of GO-SiO ${ }_{2} / \mathrm{SBR}$ and CNT$\mathrm{SiO}_{2} / \mathrm{SBR}$ composites suggested that the introduction of GO and/or CNT with large aspect ratios was beneficial in hindering the expansion of tear path, deflecting the tear path and improving the tear resistance of rubber composites during the rupture process.

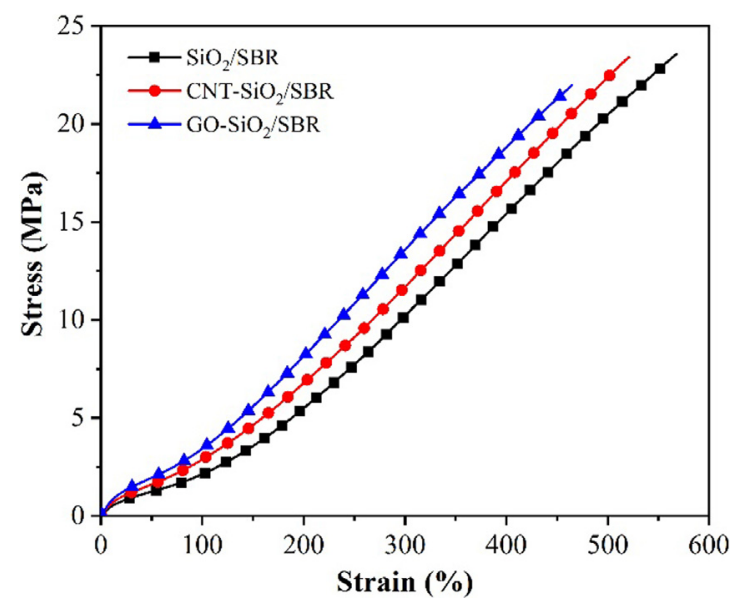

Fig. 6. The stress-strain curves of SBR composites.
Table 2

The mechanical properties of SBR composites.

\begin{tabular}{|c|c|c|c|}
\hline Samples & $\mathrm{SiO}_{2} / \mathrm{SBR}$ & $\mathrm{CNT}_{-\mathrm{SiO}_{2}} / \mathrm{SBR}$ & $\mathrm{GO} \mathrm{SiO}_{2} / \mathrm{SBR}$ \\
\hline Hardness (Shore A) & $60 \pm 0.5$ & $64 \pm 0.5$ & $70 \pm 0.4$ \\
\hline Tensile strength (MPa) & $23.1 \pm 1.5$ & $22.3 \pm 1.2$ & $20.9 \pm 1.1$ \\
\hline $\begin{array}{l}\text { Modulus at } 100 \% \text { elongation } \\
\quad(\mathrm{MPa})\end{array}$ & $2.1 \pm 0.1$ & $2.9 \pm 0.1$ & $3.5 \pm 0.1$ \\
\hline $\begin{array}{l}\text { Modulus at } 300 \% \text { elongation } \\
\text { (MPa) }\end{array}$ & $9.9 \pm 0.5$ & $11.9 \pm 0.3$ & $13.6 \pm 0.3$ \\
\hline Elongation at break (\%) & $565 \pm 15$ & $490 \pm 10$ & $441 \pm 11$ \\
\hline Tear strength $(\mathrm{kN} / \mathrm{m})$ & $45.7 \pm 3.9$ & $53.3 \pm 3.0$ & $54.8 \pm 2.8$ \\
\hline
\end{tabular}

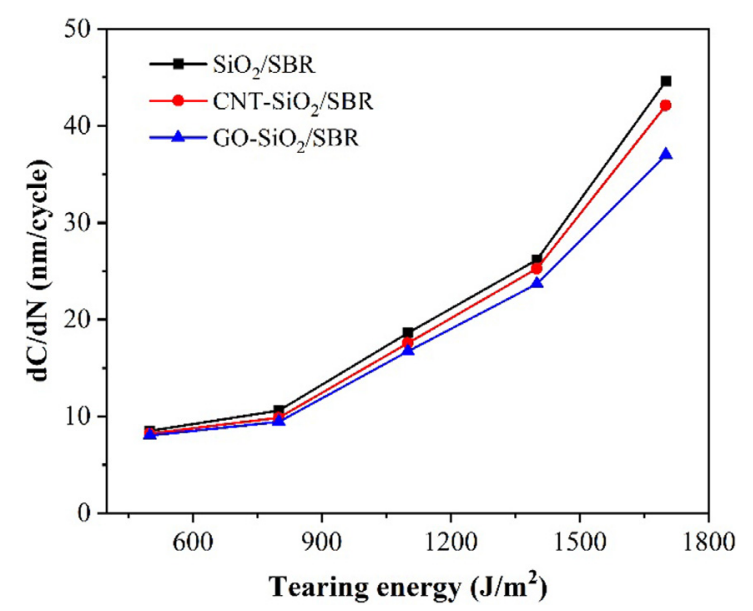

Fig. 7. Crack growth rate versus tearing energy of SBR composites.

\subsection{Fatigue properties under uniaxial loading conditions}

The crack growth rate reflects the fatigue resistance of rubber composites. The crack growth rate is mainly effected by tear energy in the fatigue process [29]. Fig. 7 shows the crack growth rates of SBR composites subjected to various tearing energies. The crack growth rates of $\mathrm{CNT}-\mathrm{SiO}_{2} / \mathrm{SBR}$ and $\mathrm{GO}-\mathrm{SiO}_{2} / \mathrm{SBR}$ composites were significantly lower than those of $\mathrm{SiO}_{2} / \mathrm{SBR}$ composites, indicating that tubular or lamellar fillers had apparent advantages in limiting and postponing crack growth. Compared with the tubular CNT, lamellar GO was shown to be superior in resisting crack growth.

To further study the microstructure evolution of the composites during fatigue, the $\mathrm{E}^{\prime}$ and $\tan \delta$ values for accumulated fatigue cycles were measured. In Fig. 8(a), it can be seen that $\mathrm{E}^{\prime}$ of rubber composites decreased rapidly in the early stage of cycling, owing to the destruction of the inial filler networks and breakage of weak crosslinking bonds. This was consistent with the phenomenon termed the Mullins effect [30]. With an increase of fatigue cycles, the fracture of physical and 

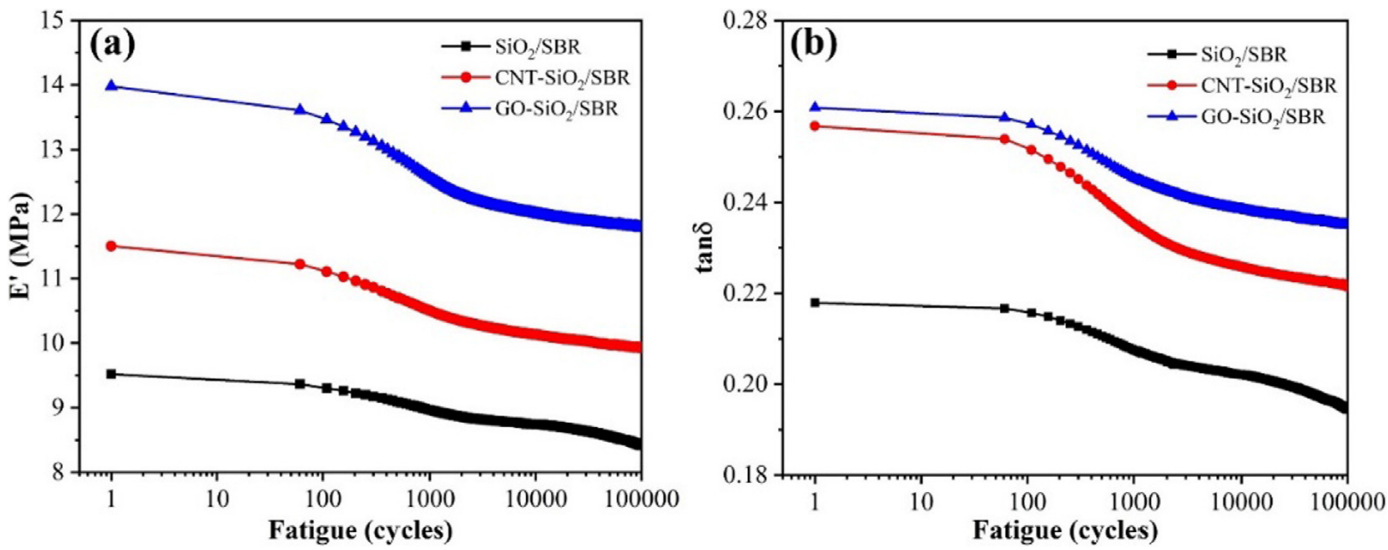

Fig. 8. The progression of (a) $E^{\prime}$ and (b) tan $\delta$ of SBR composites for different fatigue cycles.

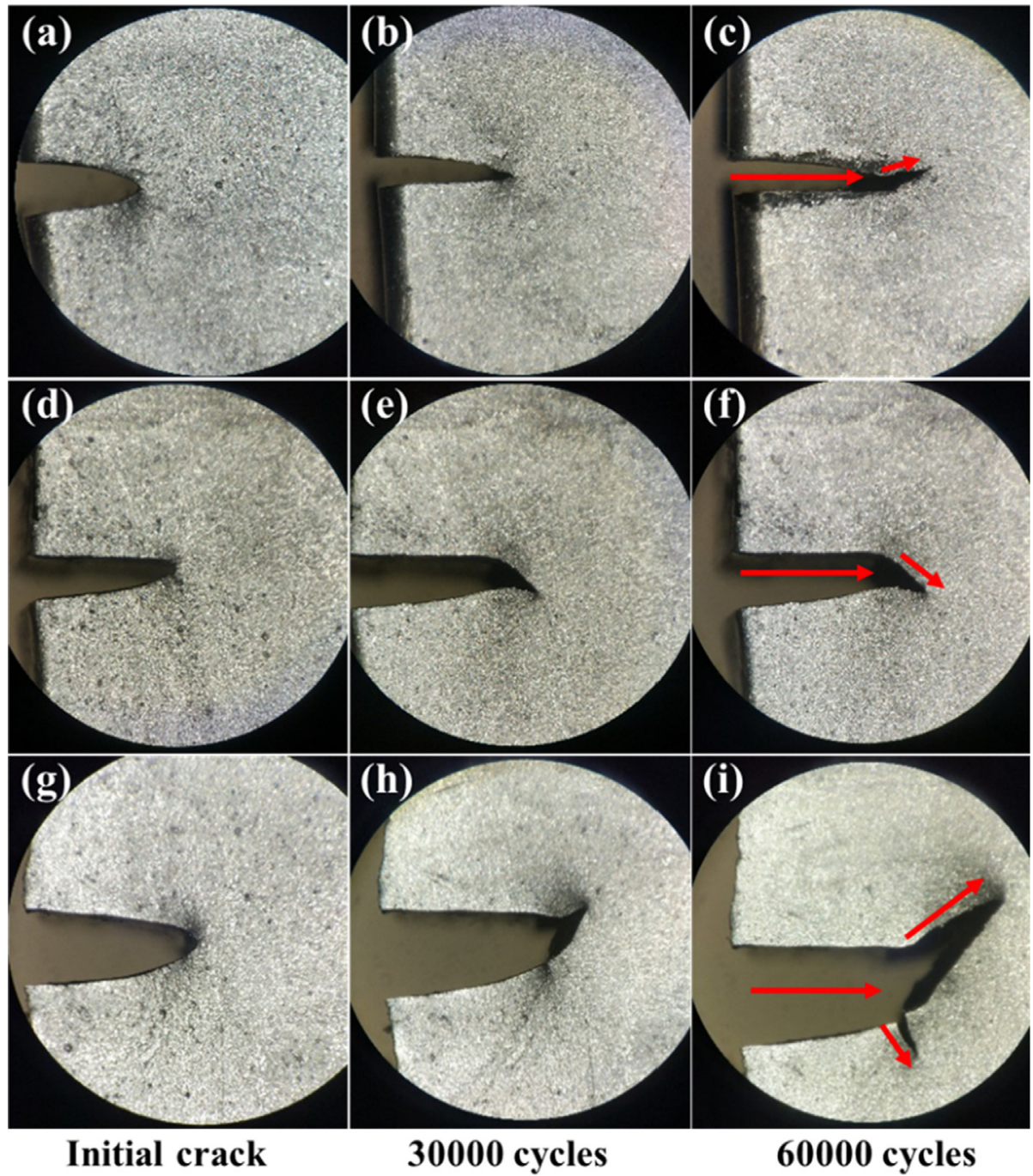

Fig. 9. Views normal to the direction of cracking for (a-c) $\mathrm{SiO}_{2} / \mathrm{SBR}$, (d-f) $\mathrm{CNT}-\mathrm{SiO}_{2} / \mathrm{SBR}$ and $(\mathrm{g}-\mathrm{i}) \mathrm{GO}-\mathrm{SiO}_{2} / \mathrm{SBR}$ composites under different fatigue cycles at a tearing energy of $1200 \mathrm{~J} / \mathrm{m}^{2}$.

chemical cross-linking points resulted in a weakening of $E^{\prime}$ in rubber composites.

By calculating the $\mathrm{E}^{\prime}$ decrease for the three samples between 10,000 fatigue cycles and 100,000 fatigue cycles, it was found that the level of decrease of $\mathrm{E}^{\prime}$ for $\mathrm{GO}-\mathrm{SiO}_{2} / \mathrm{SBR}(1.89 \%)$ composites was much smaller than that for $\mathrm{CNT}-\mathrm{SiO}_{2} / \mathrm{SBR}(2.00 \%)$ and $\mathrm{SiO}_{2} / \mathrm{SBR}(3.79 \%)$ composites, indicating that the microstructure of the $\mathrm{GO}-\mathrm{SiO}_{2} / \mathrm{SBR}$ composites were more stable under long-term fatigue loading condition. This was mainly attributed to the complex filler network composed of GO and $\mathrm{SiO}_{2}$. The complex filler network was more stable in the lengthy dynamic fatigue process and played an active role in preventing fatigue crack growth. In Fig. 8(b), the tan $\delta$ of $\mathrm{CNT}-\mathrm{SiO}_{2} / \mathrm{SBR}$ and $\mathrm{GO}-\mathrm{SiO}_{2} / \mathrm{SBR}$ composites were obviously higher than that of $\mathrm{SiO}_{2} / \mathrm{SBR}$ composites during the dynamic testing process, showing higher viscous loss for the 


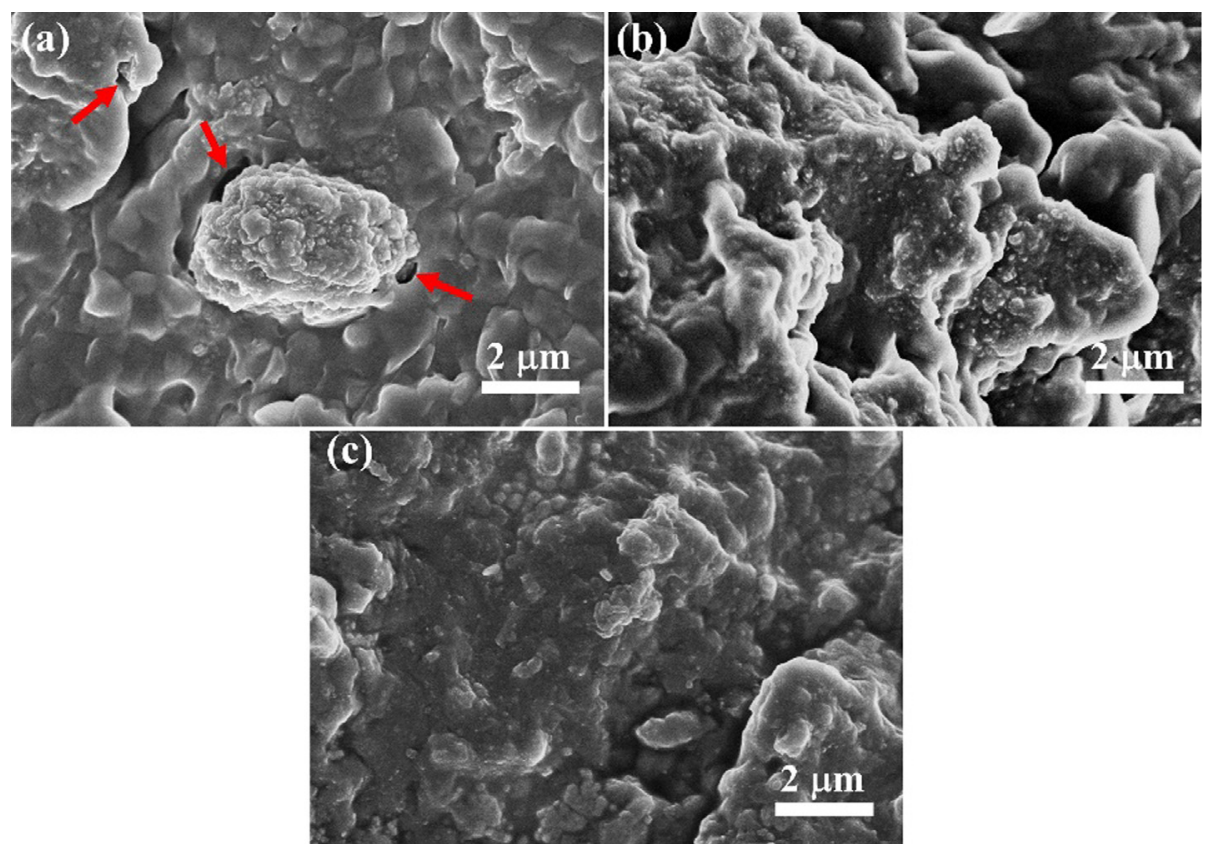

Fig. 10. The SEM images of fatigue fractured surface morphology for (a) $\mathrm{SiO}_{2} / \mathrm{SBR}$, (b) $\mathrm{CNT}-\mathrm{SiO}_{2} / \mathrm{SBR}$, (c) $\mathrm{GO}_{-} \mathrm{SiO}_{2} / \mathrm{SBR}$ composites at at a tearing energy of $1200 \mathrm{~J} /$ $\mathrm{m}^{2}$
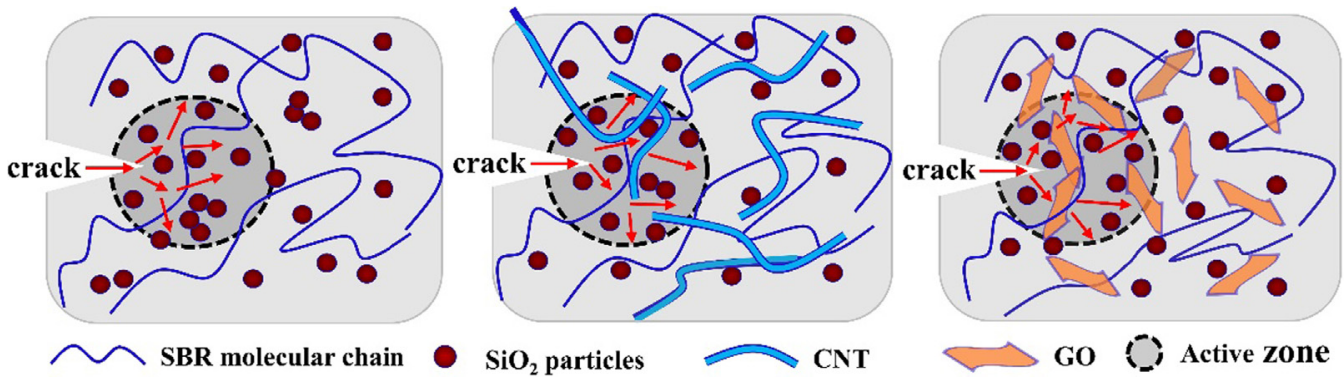

Fig. 11. Schematic of crack propagation for SBR composites.

CNT and GO filled composites which was beneficial in postponing crack propagation.

The observation of crack propagation paths could further aid the understanding of the influence of different fillers on fatigue performance of the composites [31]. As shown in Fig. 9, three representative samples with the same initial crack lengths at different fatigue cycles were selected. In Fig. 9(c), the crack propagation path of the $\mathrm{SiO}_{2} / \mathrm{SBR}$ composites was almost aligned to the initial crack. In Fig. 9(f), the crack propagation path of $\mathrm{CNT}-\mathrm{SiO}_{2} / \mathrm{SBR}$ composites showed slight deflection. More interestingly, as shown in Fig. 9(i), the main crack of the GO$\mathrm{SiO}_{2} / \mathrm{SBR}$ composites branched and generated a secondary crack. This process dissipated more energy and reduced stress concentration. The occurrence of secondary cracks was beneficial for postponing the growth rate of the main crack and improving the fatigue resistance of SBR rubber composites.

Fig. 10 shows the SEM images of fatigue fractured surfaces for the different composites. In Fig. 10(a) for $\mathrm{SiO}_{2} / \mathrm{SBR}$ composites, large $\mathrm{SiO}_{2}$ aggregates still can be observed on the fatigue fractured surface, and many voids appeared around the $\mathrm{SiO}_{2}$ aggregates (as indicated by red arrows), arising from the poor dispersion of $\mathrm{SiO}_{2}$ particles and weak interfacial interactions between $\mathrm{SiO}_{2}$ and $\mathrm{SBR}$ matrix. The large $\mathrm{SiO}_{2}$ aggregates and voids easily led to a high crack propagation rate. In Fig. 10(b)\&(c) for CNT-SiO $2 / \mathrm{SBR}$ and $\mathrm{GO}-\mathrm{SiO}_{2} / \mathrm{SBR}$ composites, few filler aggregates and voids could be observed on the fatigue fractured surface. This is mainly because tubular CNT or lamellar GO improved the dispersion of $\mathrm{SiO}_{2}$ particles in SBR matrix, resulting in fewer defects formed by large filler aggregates and contributing to the decrease in the crack propagation rate of the composites.

The schematic of crack propagation for SBR composites is shown in Fig. 11. Filler networks have a significant influence on the fatigue properties of rubber composites [8,32]. For $\mathrm{SiO}_{2} / \mathrm{SBR}$ composites, cracks are more likely to bypass $\mathrm{SiO}_{2}$ particles due to the weak interface between $\mathrm{SiO}_{2}$ aggregates and the SBR matrix. However, when CNT tubes or GO sheets are introduced into the SBR matrix, complex filler networks are formed by the CNT or GO and $\mathrm{SiO}_{2}$ particles. The breakage and reformation of the complex filler networks dissipate energy under cyclic loadings, which is benefical to the fatigue properties of rubber [6]. Meanwhile, the complex filler network inhibits the path of crack propagation and reduces the rate of crack growth. Compared with CNT, the GO sheets have a larger surface area, so the filler network constructed by $\mathrm{GO}$ and $\mathrm{SiO}_{2}$ has greater strength. Some lamellar $\mathrm{GO}$ sheets were oriented along the direction of force and perpendicular to the direction of crack propagation, which can efficiently prevent crack propagation.

\subsection{Fatigue properties under multiaxial loading conditions}

The stress-strain behavior under multiaxial loading conditions is shown in Fig. 12. The viscoelasticity of rubber composites leads to hysteresis loss during the cyclic (loading-unloading) process. The hysteresis loss area (between the loading and unloading curves) is closely related to the structure of the filler network. For most filled rubbers 

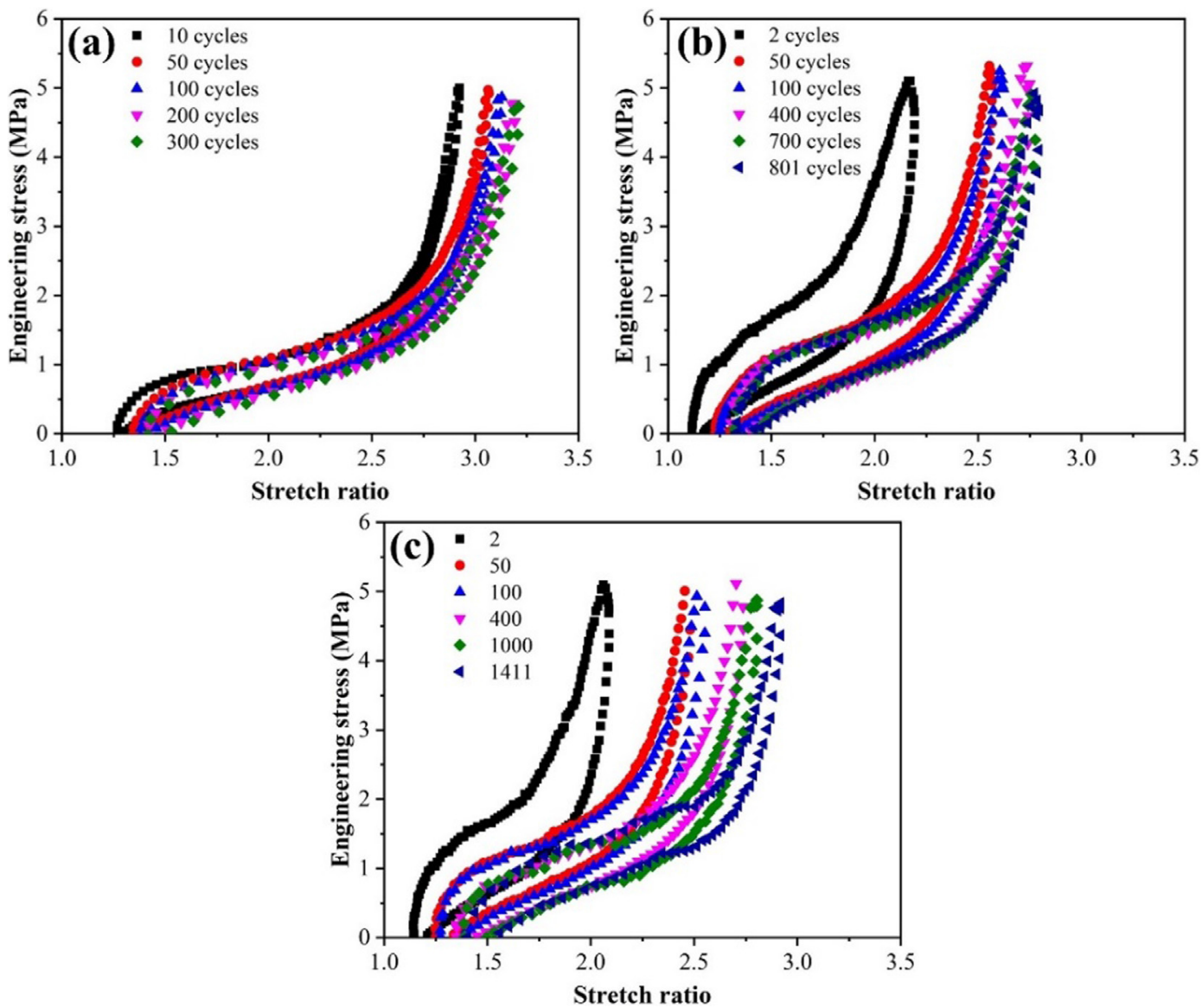

Fig. 12. Stress-strain curves of (a) $\mathrm{SiO}_{2} / \mathrm{SBR}$, (b) $\mathrm{CNT}-\mathrm{SiO}_{2} / \mathrm{SBR}$, (c) $\mathrm{GO}_{-} \mathrm{SiO}_{2} / \mathrm{SBR}$ composites at $\sigma_{\min }=0 \mathrm{MPa}$ and $\sigma_{\max }=5 \mathrm{MPa}$.

Table 3

The fatigue lives of SBR composites subjected to different $\sigma_{\max }\left(\sigma_{\min }=0 \mathrm{MPa}\right)$.

\begin{tabular}{llll}
\hline$\sigma_{\max }(\mathrm{MPa})$ & $\mathrm{SiO}_{2} / \mathrm{SBR}$ & $\mathrm{CNT}-\mathrm{SiO}_{2} / \mathrm{SBR}$ & $\mathrm{GO}-\mathrm{SiO}_{2} / \mathrm{SBR}$ \\
\hline 5 & $321 \pm 46$ & $803 \pm 154$ & $1412 \pm 227$ \\
6 & $212 \pm 24$ & $319 \pm 72$ & $965 \pm 121$ \\
7 & $161 \pm 23$ & $235 \pm 32$ & $752 \pm 98$ \\
8 & $86 \pm 12$ & $174 \pm 26$ & $425 \pm 63$ \\
9 & $76 \pm 9$ & $113 \pm 13$ & $345 \pm 37$ \\
\hline
\end{tabular}

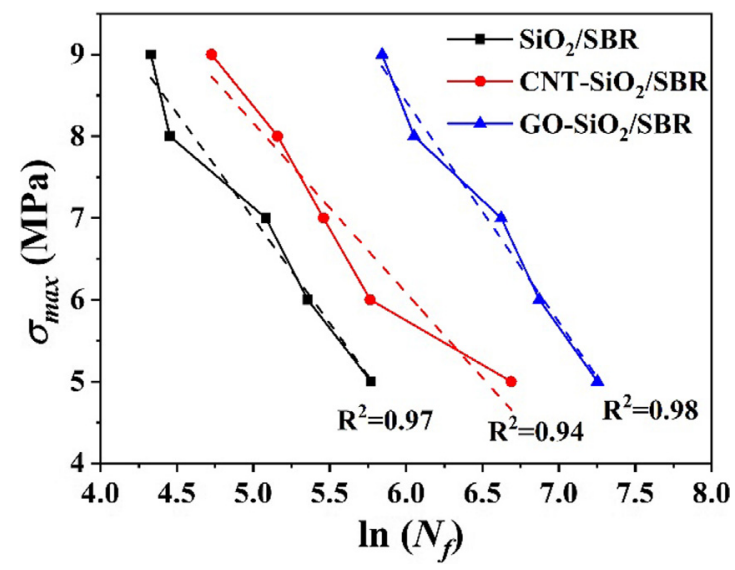

Fig. 13. $\sigma_{\max }$ versus fatigue life curves of SBR composites.

under uniaxial tensile conditions, the area of the hysteresis loop decreases gradually and becomes stable after about 100 cycles [33,34]. Also, with accumulation of cycles, the stress-strain curves become
Table 4

Values of $B_{1}$ and $B_{2}$ for the SBR composites.

\begin{tabular}{|c|c|c|c|}
\hline Composites & $B_{1}(\mathrm{MPa})$ & $B_{2}(\mathrm{MPa})$ & $\mathrm{R}^{2}$ \\
\hline $\mathrm{SiO}_{2} / \mathrm{SBR}$ & 19.83 & -2.56 & 0.97 \\
\hline $\mathrm{CNT} \mathrm{SiO}_{2} / \mathrm{SBR}$ & 18.55 & -2.08 & 0.94 \\
\hline $\mathrm{GO}-\mathrm{SiO}_{2} / \mathrm{SBR}$ & 24.63 & -2.70 & 0.98 \\
\hline
\end{tabular}

Table 5

The fatigue lives of SBR composites subjected to different $\sigma_{\min }\left(\sigma_{\max }=9 \mathrm{MPa}\right)$.

\begin{tabular}{|c|c|c|c|c|}
\hline \multirow[t]{3}{*}{$\sigma_{\min }(\mathrm{MPa})$} & \multirow[t]{3}{*}{$\sigma_{\max }(\mathrm{MPa})$} & \multicolumn{3}{|c|}{$N_{f}$} \\
\hline & & $\mathrm{SiO}_{2} / \mathrm{SBR}$ & & $\mathrm{GO}-\mathrm{SiO}_{2} / \mathrm{SBR}$ \\
\hline & & & $\mathrm{CNT}-\mathrm{SiO}_{2} / \mathrm{SBR}$ & \\
\hline 0 & 9 & $76 \pm 9$ & $113 \pm 13$ & $345 \pm 37$ \\
\hline 1 & 9 & $142 \pm 17$ & $158 \pm 28$ & $429 \pm 43$ \\
\hline 2 & 9 & $490 \pm 65$ & $774 \pm 71$ & $957 \pm 86$ \\
\hline 3 & 9 & $802 \pm 73$ & $1037 \pm 85$ & $1587 \pm 90$ \\
\hline 4 & 9 & $1029 \pm 81$ & $1190 \pm 86$ & $2401 \pm 103$ \\
\hline
\end{tabular}

superimposed. This is because the unstable filler networks and weak interactions are thoroughly destroyed under dynamic cycling and subsequently become more stable. In these fatigue tests, it is noticeable that the unstable stress-strain behavior existed from the first cycle to the last cycle under multiaxial loading conditions, indicating that the filler network changed continuously during the fatigue process. In addition, the area of the hysteresis loops of CNT-SiO ${ }_{2} / \mathrm{SBR}$ and $\mathrm{GO}-\mathrm{SiO}_{2} /$ SBR were greater than for the $\mathrm{SiO}_{2} / \mathrm{SBR}$ composites. This phenomenon proves that the hybridized $\mathrm{SiO}_{2}$ with $\mathrm{CNT}$ or GO had a synergistic effect on increasing the energy dissipation of the SBR composites.

The fatigue lives of SBR composites subjected to different $\sigma_{\max }$ levels 
are shown in Table 3. It can be seen that the fatigue life of SBR composites decreased as the engineering stress increased. Under the same $\sigma_{\max }$, the fatigue lives of $\mathrm{GO}-\mathrm{SiO}_{2} / \mathrm{SBR}$ composites were much longer than that of the other two SBR composites, owing to the complex filler network formed by $\mathrm{GO}$ and $\mathrm{SiO}_{2}$ particles and an improved filler dispersion.

The prediction of fatigue life of rubber composites is of great significance to the functionality and safety of rubber products. In previous studies, the maximum principal stress has often been used to predict the fatigue life of rubber composites [35]. Linear fitting curves for the relation of $\sigma_{\max }$ to fatigue life were obtained and shown in Fig. 13. An equation for fatigue life prediction based on $\sigma_{\max }$ is described as follows: [36]

$\ln \left(N_{f}\right)=\left(\sigma_{\max }-B_{1}\right) / B_{2}$

where $B_{1}$ and $B_{2}$ are specific constants dependent on the filler type. The values of $B_{1}$ and $B_{2}$ for SBR composites with different fillers are shown in Table 4. The $\mathrm{R}$ square value was high at 0.98 for the $\mathrm{GO}-\mathrm{SiO}_{2} / \mathrm{SBR}$ composites, showing that $\sigma_{\max }$ could be used to predict the fatigue life of the SBR composites.

Furthermore, fatigue tests were carried out at different stress amplitudes with a fixed $\sigma_{\max }$. The fatigue life increased as the $\sigma_{\min }$ increased for the three samples, as shown in Table 5. This was because increasing the $\sigma_{\min }$ led to smaller strain amplitudes, subsequently reducing the destruction of filler networks and a loss in viscosity. Under the same stress amplitudes, the fatigue life of $\mathrm{GO}-\mathrm{SiO}_{2} / \mathrm{SBR}$ was also longer than that of the other two composites, owing to the uniformly of the dispersed two-dimensional GO sheets being more likely to hinder crack propagation.

Combining the fatigue results for both uniaxial and multiaxial conditions, it is clear that the improved fatigue life of $\mathrm{GO}-\mathrm{SiO}_{2} / \mathrm{SBR}$ composites is attributed to the following: (1) An excellent synergistic dispersion was formed between two-dimensional GO sheets and spherical $\mathrm{SiO}_{2}$ particles, and a strong filler network was constructed. The interfacial friction of the filler network dissipated more energy, resulting in a lower rate of crack propagation. (2) GO sheet had a strong interfacial interface with SBR chains due to its two-dimensional lamellar structure. Therefore, stress was effectively transferred from the SBR matrix to the GO sheets, avoiding possible stress concentration and rapid fracture. (3) The two-dimensional sheet structure of GO was more likely to form an oriented structure to some extent, which was perpendicular to the crack propagation direction at the crack tip. The orientation structure was beneficial to the crack defecting and branching under cyclic deformation, further forming secondary cracks and reducing the crack growth rates of the main cracks. The synergistic effect between different dimensional fillers provides elastomer research with a new strategy for improving the fatigue resistance properties of rubber composites.

\section{Conclusions}

The effects of the introduction of CNT or GO into SBR composites on the microstructure and performance were investigated. The results indicated that tubular CNT or lamellar GO were more likely to intercalate the $\mathrm{SiO}_{2}$ particles, subsequently constructing a strong complex filler network and an improved filler dispersion in the SBR composites. The synergistic effect between $\mathrm{CNT}$ (or GO) and $\mathrm{SiO}_{2}$ improved the physical and mechanical properties of SBR composites. The introduction of CNT or $\mathrm{GO}$ into $\mathrm{SiO}_{2} / \mathrm{SBR}$ composites led to the crack propagation path becoming more prone to deflection, and low crack growth rate. Under multiaxial fatigue conditions, it was found that $\sigma_{\max }$ can be used as a reliable fatigue life predictor for SBR composites. For both uniaxial fatigue and multiaxial fatigue testing, $\mathrm{GO}-\mathrm{SiO}_{2} / \mathrm{SBR}$ composites exhibited the lowest crack growth rate and the longer fatigue lives compared with the $\mathrm{CNT}-\mathrm{SiO}_{2} / \mathrm{SBR}$ and $\mathrm{SiO}_{2} / \mathrm{SBR}$ composites.

\section{Declaration of Competing Interest}

The authors declare that they have no known competing financial interests or personal relationships that could have appeared to influence the work reported in this paper.

\section{Acknowledgments}

This work was supported by the National Key R\&D Program of China (2017YFE0126800), the National Natural Science Foundation of China (51573007) and the National Basic Research Program of China (2015CB654700(2015CB654705)).

\section{References}

[1] Peddini SK, Bosnyak CP, Henderson NM, Ellison CJ, Paul DR. Nanocomposites from styrene-butadiene rubber (SBR) and multiwall carbon nanotubes (MWCNT) part 2: Mechanical properties. Polymer 2015;56:443-51.

[2] Dong B, Liu C, Lu Y, Zhang L, Wu Y. Effects of hybrid filler networks of carbon nanotubes and carbon black on fracture resistance of styrene-butadiene rubber composites. Polym Eng Sci 2016;56:1425-31.

[3] Legorju-jago K, Bathias C. Fatigue initiation and propagation in natural and syn thetic rubbers. Int J Fatigue 2002;24:85-92.

[4] Saintier N, Cailletaud G, Piques R. Crack initiation and propagation under multiaxial fatigue in a natural rubber. Int J Fatigue 2006;28:61-72.

[5] Tee YL, Loo MS, Andriyana A. Recent advances on fatigue of rubber after the literature survey by Mars and Fatemi in 2002 and 2004. Int J Fatigue 2018;110:115-29.

[6] Li H, Yang L, Weng G, Xing W, Wu J, Huang G. Toughening rubbers with a hybrid filler network of graphene and carbon nanotubes. J Mater Chem A 2015;3:22385-92.

[7] Dong B, Liu C, Lu Y, Wu Y. Synergistic effects of carbon nanotubes and carbon black on the fracture and fatigue resistance of natural rubber composites. J Appl Polym Sci 2015;132.

[8] Rooj S, Das A, Morozov IA, Stöckelhuber KW, Stocek R, Heinrich G. Influence of "expanded clay" on the microstructure and fatigue crack growth behavior of carbon black filled NR composites. Compos Sci Technol 2013;76:61-8.

[9] Klüppel M. The role of filler networking in fatigue crack propagation of elastomers under high-severity conditions. Macromol Mater Eng 2009;294:130-40.

[10] Le Cam JB, Huneau B, Verron E, Gornet L. Mechanism of fatigue crack growth in carbon black filled natural rubber. Macromolecules 2004;37:5011-7.

[11] Dong B, Liu C, Wu Y. Fracture and fatigue of silica/carbon black/natural rubber composites. Polym Test 2014;38:40-5.

[12] Harbour RJ, Fatemi A, Mars WV. Fatigue life analysis and predictions for NR and SBR under variable amplitude and multiaxial loading conditions. Int J Fatigue 2008;30:1231-47.

[13] Kim JH, Jeong HY. A study on the material properties and fatigue life of natural rubber with different carbon blacks. Int J Fatigue 2005;27:263-72.

[14] Zheng J, Han D, Ye X, Wu X, Wu Y, Wang Y, et al. Chemical and physical interaction between silane coupling agent with long arms and silica and its effect on silica/ natural rubber composites. Polymer 2018;135:200-10.

[15] Huneau B, Masquelier I, Marco Y, Saux VL, Noizet S, Schiel C, et al. Fatigue crack initiation in a carbon black-filled natural rubber. Rubber Chem Technol 2016;89:126-41.

[16] Xie Z, Fu X, Wei L, Luo M, Liu Y, Ling F, et al. New evidence disclosed for the engineered strong interfacial interaction of graphene/rubber nanocomposites. Polymer 2017;118:30-9.

[17] Dong B, Liu C, Zhang L, Wu Y. Preparation, fracture, and fatigue of exfoliated graphene oxide/natural rubber composites. RSC Adv 2015;5:17140-8.

[18] Zhou X, Wang L, Cao X, Yin Q, Weng G. Crack resistance improvement of rubber blend by a filler network of graphene. J Appl Polym Sci 2019;136:47278.

[19] Dong B, Zhang $\mathrm{L}, \mathrm{Wu} \mathrm{Y}$. Influences of different dimensional carbon-based nanofillers on fracture and fatigue resistance of natural rubber composites. Polym Test 2017;63:281-8.

[20] Hummers WS, Offeman RE. Preparation of graphitic oxide. J Am Chem Soc 1958;80:1339.

[21] Mao Y, Wen S, Chen Y, Zhang F, Panine P, Chan TW, et al. High performance graphene oxide based rubber composites. Sci Rep 2013;3:2508.

[22] Kaang S, Jin YW, Huh Y-I, Lee W-J, Im WB. A test method to measure fatigue crack growth rate of rubbery materials. Polym Test 2006;25:347-52.

[23] Zhou Y, Jerrams S, Betts A, Chen L. Fatigue life prediction of magnetorheological elastomers subjected to dynamic equi-biaxial cyclic loading. Mater Chem Phys 2014;146:487-92.

[24] Zhou Y, Jerrams S, Chen L. Multi-axial fatigue in magnetorheological elastomers using bubble inflation. Mater Des 2013;50:68-71.

[25] Gao W, Lu J, Song W, Hu J, Han B. Solution mechanochemical approach for preparing high-dispersion $\mathrm{SiO}_{2}$-g-SSBR and the performance of modified silica/SSBR composites. Ind Eng Chem Res 2019;58:7146-55.

[26] Sun C, Wen S, Ma H, Li Y, Chen L, Wang Z, et al. Improvement of silica dispersion in solution polymerized styrene-butadiene rubber via introducing amino functional groups. Ind Eng Chem Res 2019;58:1454-61. 
[27] Zhang S, Zheng L, Liu D, Xu Z, Zhang L, Liu L, et al. Improved mechanical and fatigue properties of graphene oxide/silica/SBR composites. RSC Adv 2017;7:40813-8.

[28] Payne AR. The dynamic properties of carbon black loaded natural rubber vulcanizates. Part II. J Appl Polym Sci 1962;6:368-72.

[29] Rivlin RS, Thomas AG. Rupture of rubber. I. characteristic energy for tearing. J Polym Sci 1953;10:291-318.

[30] Mullins L. Softening of rubber by deformation. Rubber Chem Technol 1969;42:339-62.

[31] Weng G, Yao H, Chang A, Fu K, Liu Y, Chen Z. Crack growth mechanism of natural rubber under fatigue loading studied by a real-time crack tip morphology monitoring method. RSC Adv 2014;4:43942-50.
[32] Liu Y, Li L, Wang Q, Zhang X. Fracture properties of natural rubber filled with hybrid carbon black/nanoclay. J Polym Res 2011;18:859-67.

[33] Brieu M, Diani J, Mignot C, Moriceau C. Response of a carbon-black filled SBR under large strain cyclic uniaxial tension. Int J Fatigue 2010;32:1921-7.

[34] Merckel Y, Diani J, Brieu M, Berghezan D. Experimental characterization and modelling of the cyclic softening of carbon-black filled rubbers. Mater Sci Eng, A 2011;528:8651-9.

[35] Abraham F, Alshuth T, Jerrams S. The effect of minimum stress and stress amplitude on the fatigue life of non strain crystallising elastomers. Mater Des 2005;26:239-45.

[36] Zhou Y, Jerrams S, Betts A, Farrell G, Chen L. The influence of particle content on the equi-biaxial fatigue behaviour of magnetorheological elastomers. Mater Des 2015;67:398-404. 